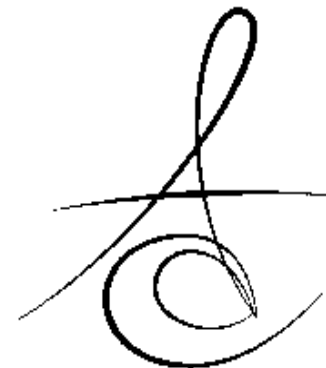

Makale Kodu/Article code: 1113

Makale Gönderilme tarihi: 04.03.2013

Kabul Tarihi: 21.03..2013

\section{DİŞ HEKİMLİĞİNDE ERGONOMİ}

DENTAL ERGONOMICS

Arş.Gör.Dt.Emre TOKAR*

\author{
Ars.Gör.Dt.Nihal PEHLIVAN*
}

\section{ÖZET}

Diş hekimlerinin dar bir çalışma alanında tekrarlayıcı hareketlerde bulunmaları, yüksek hassasiyete sahip aletler kullanmaları ve sürekli belli bir pozisyonda durmaları nedeniyle ağrı açısından risk altındadır. Kas iskelet sisteminde görülen ağrıların yanı sıra sebepsiz yorgunluk, uyku bozuklukları, huzursuzluk gibi durumlara da rastlanılmaktadır. Diş hekimliğinde ergonomi tekniklerinin uygulanmasıyla, postural bozukluklar önlenerek; kas dengesizlikleri, kas nekrozları ve omurga disk dejenerasyonu gibi patolojik değişikliklerin ortaya çıkması engellenebilir. Ayrıca, çalışma alanının doğru şekilde düzenlenmesi ile de bu patolojik durumlar önlenebilir. Düzenli egzersiz programlarının, doğru postür ve pozisyon stratejilerinin uygulanması, uygun çalışma alanı düzeninin oluşturulması ile diş hekimi mesleğini uzun yıllar başarılı ve sağlıklı bir şekilde sürdürülebilir.

Anahtar Kelimeler: İnsan mühendisliği, Kasiskelet ağrısı, Mesleki diş hekimliği.

\section{ABSTRACT}

Dentists are at risk in terms of pain, because of usually hold on particular position, use of highly precision instruments and make repetitive movements in narrow field of study. As well as pain in the musculoskeletal system, dentist could be encountered with reasonless fatigue, sleep disturbances, restlessness. Avoidance of postural deficiencies, as well as subsequent pathological changes, such as muscle imbalances, muscle necrosis and spinal disk degeneration could be prevented assuring the application of ergonomics in dentistry. Exercises in accordance with advice of a physician should be done daily, the spaces between appointments and small breaks into the treatment session. Dentists could mantain their profession successfully and healthily long time carrying out regular excersize program, accurate posture and postioning strategies.

Keywords: Human engineering, Musculoskeletal pain, Occupational dentistry

\section{GİRİş}

Ergonomi; "çalışılan ve yaşanan çevrenin insan özelliklerine uygun olarak tasarımlanması çalışması" disiplini veya "insan ile çalışma yeri çevresi arasındaki ilişkinin bilimsel incelenmesi" olarak tanımlanabilir. Ergonomi sözcüğü, Yunanca "ergo"(iş) ve "nomos"(kural/yasa) sözcüklerinden oluşmaktadır. Basit terminolojiyle ergonomi, aletin, ekipmanın, çalışma alanının ve görevlerin tasarlanmasıyla işin çalışana uygun hale getirilmesiyle, çalışmayı zorlaştırıcı değil kolaylaştırıcı bir yoldur. ${ }^{1}$ Ergonominin amaçları;

- Çalışanın sağlığının ve iş güvenliğinin sağlanması,

- İşgücü kayıplarının önlenmesi,

- Yorulmanın ve iş stresinin azaltılması,

- İş kazaları ve mesleki risklerin azaltılması,

- Verimlilik ve kalitenin yükseltilmesi,

- Çalışma sahasının güvenli, sağıkklı ve rahat hale getirilmesini sağlamaktır. ${ }^{1}$

*Gazi Üniversitesi Diş Hekimliği Fakültesi Protetik Diş Tedavisi ABD 
Diş hekimleri lokalize ve dar bir alanda çalışmaları, tekrar edici ve güç sarf ettirici hareketlerde bulunmaları, kas iskelet sisteminde mekanik stres oluşturan teknik aletler kullanmaları ve sürekli belli bir pozisyonda durmaları nedeniyle ağrı açısından risk altındaki meslek çalışanları arasındadır. Günlük yaşam aktivitesi sırasında yapılan zorlayııı hareketler, maruz kalınan fizyolojik travmalar, dinlenme olmaksızın yapılan egzersizler yanında, çalışma ortamında kullanılan teknik aletler, statik postür, hassas çalışma, uzun tedavi süresi, yaş, doğal olmayan çalışma pozisyonları ve beden kitle indeksi kas iskelet sistemine bağı ağrılarda etken önemli faktörlerdir. ${ }^{2-4}$ Ayrıca, diş hekimlerinde, karpal tünel sendromunu da içeren üst ekstremite kas iskelet rahatsızlığı görülme sıklı̆ı yüksektir. ${ }^{5}$ Kas iskelet rahatsızıkları omuzlarda, boyunda, sirt ve bel bölgesinde, el, bilek ve dirseklerde ağrıyla ortaya çıkmaktadır. ${ }^{6}$ Çalışmayla ilişkili kas iskelet rahatsızığının yansıra, sebepsiz yorgunluk, uyku bozuklukları, huzursuzluk gibi durumlara da rastlanmaktadır. $^{7}$ Diş hekimliğinde ergonomi tekniklerinin uygulanmasıyla, postural bozukluklar önlenerek; kas dengesizlikleri, kas nekrozları ve omurga disk dejenerasyonu gibi patolojik değişikliklerin ortaya çıkması engellenebilmektedir. ${ }^{8}$ Ayrıca, bilişsel ve fiziksel stres azaltılıp, diş hekimliği ile ilişkili mesleki rahatsızlıklar da önlenerek, üretkenlik arttırıır, böylece hem hekim hem de hasta için daha iyi kalite ve konfor sağlanmış olmaktadır. ${ }^{9}$

1977 yılında Dünya Sağlık Örgütü (WHO) tarafından diş hekimliği tedavilerine uluslararası ergonomik standart getirilmiştir. Bu standartta anahtar husus, doğru çalışma postürünün benimsenmesidir. Bu standartta belirtildiği üzere mümkün olduğu kadar çok oturarak çalışıldığında, bacaklarda ve pelviste yorgunluk hissi azalmaktadır. ${ }^{10}$

Ayakta duruş postüründe, omurga dört doğal eğriye sahiptir; servikal lordoz, torakal kifoz, lumbal Iordoz ve sakral kifoz. ${ }^{11}$ Bu eğriler aşırı eğimlendiğinde veya düzleştiğinde, omurga dik vaziyette durmak için kaslara, ligamentlere veya yumuşak dokuya intiyaç duymaktadır. Diş hekimlerinde sıklıkla desteksiz oturma sonucunda lumbal lordozda düzleşme görülmektedir. Kemik altyapı omurgaya daha az desteklik sağlamakta ve omurga; arkadaki kaslar, ligamentler ve bağ dokusu tarafından desteklenmekte ve dokularda gerilime, iskemi oluşmasına ve tetik noktası oluşumuna sebebiyet verebilmektedir. Lumbal eğrideki bu düzleşme aynı zamanda, omur diskinin çekirdeğinin arkaya yani omuriliğe doğru hareketine sebep olmaktadır. Zamanla, diskin arka duvarı zayıflamaya başlamakta ve disk hernisi (fitık) meydana gelebilmektedir. Bu sebeple, hekimin en uygun lumbal lordoz pozisyonunu sağlayabilecek durumda olması gerekmektedir. ${ }^{10}$

Ergonomik çalışma ortamı sağlanarak, basit önlemler alınarak, düzenli egzersizler yapılarak, daha sağlıkı ve verimli çalışmaya imkan verilebilmektedir. Bu sayede, diş hekimlerinde çalışmayla ilişkili kas iskelet rahatsızlığı ve bel ağrıları ortaya çıkma riski azaltılabilir. Bunun için aşağıda ele alınan konuların önemi büyüktür.

\section{Oturma Postürü}

Diş hekimleri çalışma esnasında, aynı statik postürde uzun süre kalmaktadırlar. Uygun oturma postüründe bile, vücuttaki kasların yarısı statik olarak kasılmaktadır ve omur eklemleri arasında az da olsa bir hareketlilik olmaktadır. Bu mikro değişiklikler sırt, boyun ve omuzlarda kas iskelet rahatsızlıklarına neden olmaktadır. ${ }^{12-15}$

Uygun olmayan postüral duruş; omurlar, diskler, kaslar ve ligamentlerdeki aşınma ve yırtımayı hızlandırmakta, bu da ağrıya sebebiyet vermektedir. Disk baskısı, diş hekimlerinin sıkıkla yaptığı hareketler olan oturma, öne doğru eğilme ve dönme hareketlerinde dramatik şekilde artmaktadır. (Resim 1) Diş hekimi sandalyede otururken hastasına doğru eğildiğinde, lumbal eğri düzleşmektedir. Omurga, kemik yapılarla değil arkadaki kas, ligament ve yumuşak dokular tarafindan desteklenmektedir. Bu da belde aşııı kuvvetlerin meydana gelmesine, kas gerinmelerine ve ağrıı tetik noktalarının oluşmasına neden olmaktadır. Ayrıca, uyluklar yere paralel olacak şekilde oturmak, eğilme esnasında pelvisin geriye doğru dönmesine, bel eğrisinin düzleşmesine, kas geriniminde ve disk baskısında artmaya sebep olmaktadır. Uylukların aşağıya doğru eğimlendirilmesi normal bel eğiminin oluşmasına, böylece bel kaslarında gerinimin ve ağrının azalmasına sebep olmaktadır. (Resim 2) Sırta gelen baskıyı azaltmanın en iyi yolu ayakta durmaktır. Ancak, hekimin zaman zaman oturmaya da intiyacı vardır. Oturma esnasında, vücudun esas ağırlığı koltuğa iletilmektedir. Geri kalan ağırlık da yere, arka desteğe ve kol desteğine iletilmektedir. Ağırlığın transferinde anahtar, koltuk tasarımıdır. Uygun destek sağlanamazsa, sırtta ve 
belde istenmeyen basınçlar oluşur, bu da ağrı oluşumuna sebep olmaktadır. Disk baskısını azaltmak için lumbal omurların desteklenmesine intiyaç vardır. Aşırı bel baskısını önlemede lumbal destek kritik öneme sahiptir. Bunu sağlamak için koltuk hekimin arkasına doğru eğimli olmalıdır. Koltuğun arka destek bölgesinde $120^{\circ}$ eğim ve $5 \mathrm{~cm}^{\prime}$ lik lumbal destek sahasına sahip olması, bel bölgesine gelen basıncı en aza indirgemektedir. ${ }^{1,8,16}$

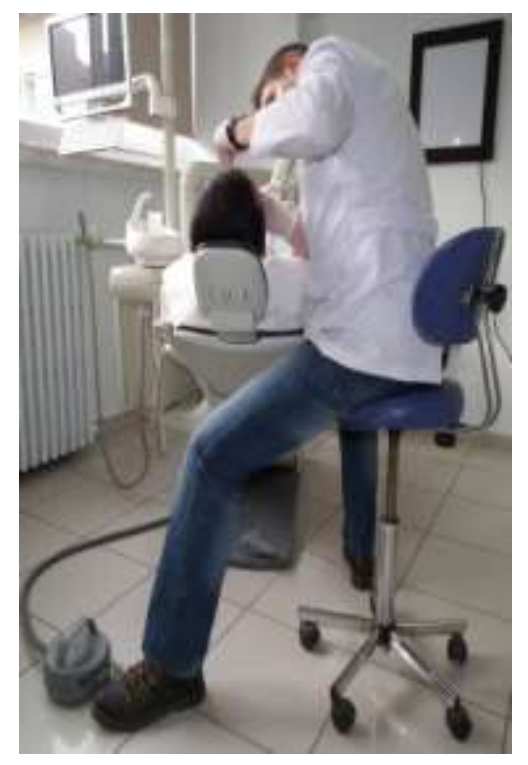

Resim 1. Hekimin pedala ulaşmak için ayağını uzatması ve iyi bir görüş sağlamak için hasta üzerine eğilmesi.

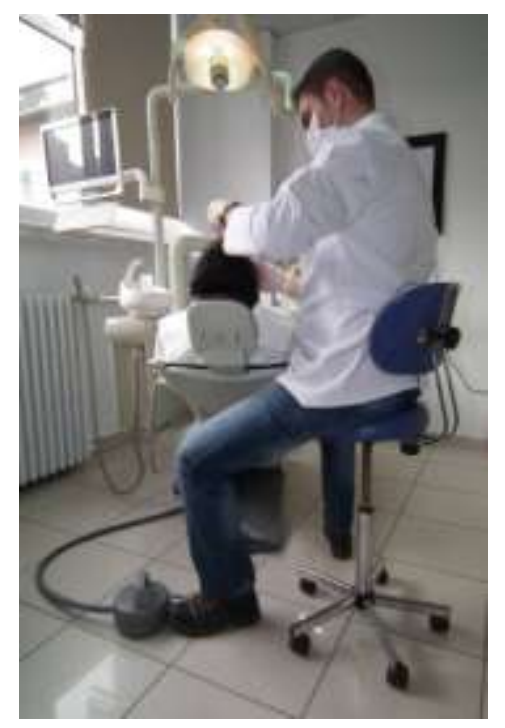

Resim 2. Normal bel eğiminin sağlanması için uylukların aşağıya doğru eğimlendirilmesi.

\section{Diş Hekimi Koltuğu Ergonomisi}

Diş hekimi çalışma koltuğu; hareketi ve hastaya ulaşmayı kolaylaştıracak şekilde olmalıdır. Tek bir boyutun bütün hekimler için ideal olmaması nedeniyle, çalışma koltuğu hekimin vücut ölçülerine uyacak şekilde planlanmalıdır. ${ }^{1,17}$ Koltuğun aşağıdaki özellikleri sağlaması önemlidir;

- Stabil olmalı (5 ayaklı, tekerlekli),

- Lumbal desteklik sağlamalı,

- Ayarlanabilir gövdeyi saran desteği olmalı,

- Arka desteği ayarlanabilmeli,

- Koltuk yüksekliği ayarlanabilmeli,

- Eller-serbest koltuk yükseklik ayarı yapılabilmeli,

- Ayarlanabilir ayak destekleri bulunmalı,

- Dikişsiz döşemeye sahip olmalı,

- Dokunmuş koltuk materyaline sahip olmalı,

- Eğimli koltuk teknesi olmalı,

- Doğru tekerlek tipi seçilmeli,

- Kol desteği (opsiyonel) bulunmalıdır., ${ }^{1,8}$

\section{Hasta Koltuğu Ergonomisi}

Hasta koltuğunun tasarımı, hasta konforunu sağlamayı ve en üst düzeyde hastaya ulaşılabilirliği amaçlamalıdır. Hasta koltuğu aşağıdaki özelliklere sahip olmalıdır;

- Stabil olmalı,

- Hastanın giriş çıkışı için döner veya aşağı açılan kol destekleri bulunmalı (Hekimin saat 8:00-10:00 pozisyonları arasında dizlerinin sabit metal desteklere çarpmadan çalışmasına olanak tanımalı),

- Diş hekimi için ek ön kol/bilek desteğine sahip olmalı,

- Baş desteği ayarlanabilmeli,

- Eller-serbest kontrol yapilabilmeli,

- Bacaklara daha geniş yer için, baş desteği küçük ince olmalı,

- Hekimin hastaya yakın konumlanması için sırt desteği dar olmalı,

- Dönme özelliği olmalı,

- Küçük düğmeleri olmalı (büyük düğmeler, hekimin koltuğuna çarparak yakın pozisyonda konumlanmasına engel olur),

- Koltuk yüksekliği ve eğimi ayarlanabilmelidir., ${ }^{1,8}$

\section{Çalışma Alanı Düzeni}

Dental ünitte; başlıklar, hava/su tabancası ve el aletleri hastanın önünde (avrupa stili servis sistemi) veya arkasında (geri servis sistemi) konumlanabilir. Hastanın önünde konumlanan sistemde, aletlere

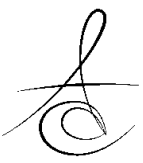


ulaşmak için hekimin eğilmesine gerek yoktur. Hastanın arkasında konumlanan sistemde, diş hekimi gerekli olan objeyi alıp tekrar yerine koymak için kolunu uzatmak ve/veya gövdesinin üst kısmını eğmek zorunda kalmakta, sonuçta bel ağrısı ortaya çıkmaktadır. ${ }^{18}$ Tabladan aletleri almak için en yakındaki el kullanılmalıdır ve sonra çalışılan ele alet aktarılmalıdır. (Resim 3, 4) Hastanın pozisyonu, diş hekiminin dirseklerini $30^{\circ}$ den fazla kaldırmayacağı şekilde ayarlanmalıdır. ${ }^{1,8}$ (Resim 2) El aletleri diş hekiminin görüş alanı içersinde $20-25 \mathrm{~cm}$ uzaklıkta bulunmalıdır.,17 Hastanın ağzıyla hekimin gözleri arasındaki $35-40$ cm'lik mesafe idealdir. ${ }^{4}$ Çalışma alanının düzeninde;

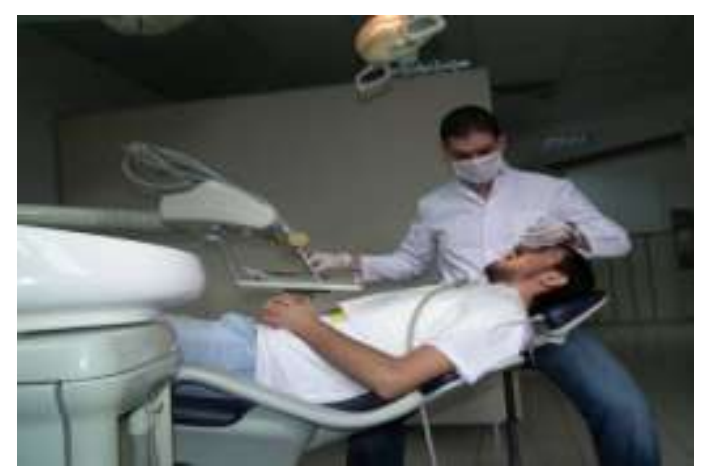

Resim 3. Tablanın aletlere kolaylıkla ulaşılabilecek pozisyonda konumlanması.

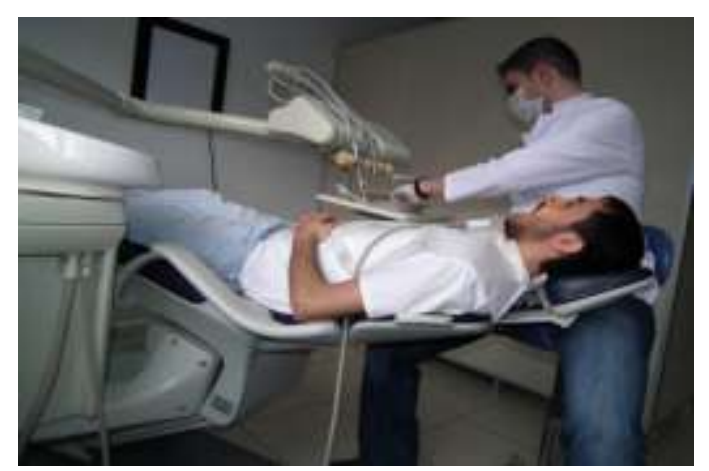

Resim 4. Tabladan aletlerin uzaktaki el ile gövdeyi bükürek alınması.

- Alet, materyal, ilaç gibi tedavide kullanılacak araç-gereç hekimin otururken ulaşılabileceği pozisyonda olmalı,

- Kablolar vücuttan uzakta konumlanmalı,

- Çalışma düzeni farklı uygulayıcılar için ayarlanabilmelidir. ${ }^{1}$
Günümüzde diş hekimliği çalışma alanın düzenlenmesinde dört-elli diş hekimliği konseptinin uygulanması, stres ve yorgunluğu azaltmakta, üretkenliği ve verimliliği arttırmaktadır. ${ }^{19}$ (Resim 5) Yardımcısız çalışmada ilave süreye intiyaç vardır. Hekimin aletlere ulaşma ve işlem yapma esnasında uygun çalışma pozisyonundan uzaklaşılmaktadır. ${ }^{8}$

Çalışma ortamında, gürültülü çalışan araçların bulundurulmamasına önem gösterilmelidir. Eğer mecbur kalınıyorsa ses yalıtımı sağlanmalıdır. Çünkü 80 desibel üstündeki ses insan sağlığını psikolojik olarak olumsuz etkilerken, 100 desibel üstündeki ses organik bozukluklara neden olmaktadır. Gürültülü ortam hekimin dikkatinin bozulmasına ve hatalı uygulamalar yapmasına sebep olabilmektedir. ${ }^{17}$

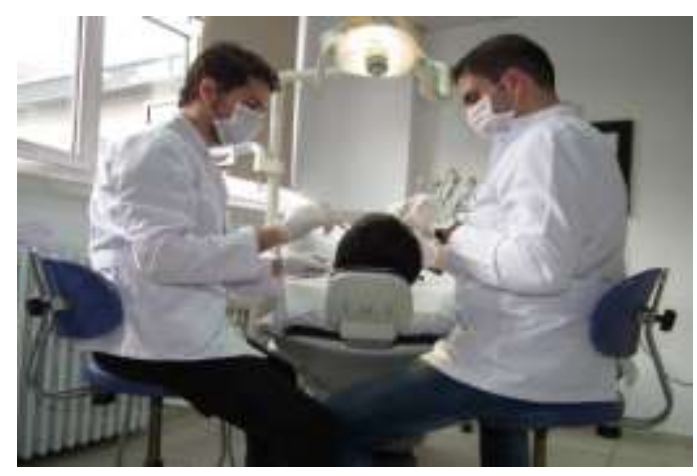

Resim 5. Dört-elli diş hekimliği konsepti.

\section{Kol Destekleri}

Lumbal disk baskısını azaltmada alınacak önlemlerden biri de kol destekleri kullanmaktır. Kol destekleri bel, boyun ve omuzdaki stresi azaltmaktadır. Bu destekler, kuvvetin dağılımında koltuk ve arka desteğe yardımcı olmaktadır. ${ }^{1,12}$ Hassas çalışma için daha küçük kasların çalıştığı durumlarda yükseklik ayarlanarak, omuzlara aşırı stres gelmesi engellenmelidir. ${ }^{1,8}$

\section{Kalça Eklemi Açısını Açmak}

Kalça eklemi açısını açmak için eğimli oturma düzlemi veya eğer koltuklar kullanılabilir. Eğimli olmayan koltuklara kolaylıkla uyarlanabilen ergonomik minderler kullanılarak kalça eklemi açıSı $110^{\circ}$ ye kadar açılabilmektedir. ${ }^{1,4,8}$

Gövdenin öne doğru itimini sağlamaya yardımcı diğer bir tasarım da eğer koltuklardır. Bu tip koltuklar genellikle ayakta oturma taburelerine benzemektedir. Kalça eklemi açısını $135^{\circ}$ ye kadar açabilmektedir. Bu koltukta oturan hekim, oturma ile ayakta durma

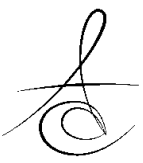


arasındaki bir pozisyonda olduğunu bilmeli, bu durumda geleneksel koltuğa oranla bele daha az baskı iletilmektedir. ${ }^{1,8}$

\section{Arka Desteğin Ayarlanması}

Koltuğun arka destek bölgesinin en tümsek kısmı, diş hekiminin belinin eğimine adapte olacak şekilde ayarlanmalıdır. ${ }^{1,8,12}$ (Resim 2) Bu ayarlamayla kas aktivitesinde ciddi oranda azalma olmaktadır. Ayrıca bu pozisyonda vücudun tamir kapasitesiyle orantılı olarak aşırı derecedeki hasar ve mikro travmanın onarımına izin verilmektedir. ${ }^{1,8}$

\section{Çok Düşük Koltuk Yüksekliğinden}

\section{Kaçınmak}

Diş hekimi öncelikle kendi koltuğunu ayarlamalıdır. Önce hasta koltuğunun daha sonra da hastaya göre hekimin kendi koltuğunu ayarlaması sıklıkla yapılan hatadır. ${ }^{8}$ Diş hekiminin koltuğu çok düşük olarak ayarlandığında, kalça ve diz eklemi açıları keskin olmaktadır ve vücut ağırlığı bacakların arkasına doğru dağıtılmak yerine, çok dar alanda oturan kemiklere iletilmektedir. Bu durumda karın bölgesindeki organlarda sıkışma ve omurgada düzleşmeyle birlikte bel ağrısı meydana gelmektedir. ${ }^{1,8,12}$

\section{Kısa Çalışma Mesafesinden Kaçınmak}

Diş hekimliğinde çalışma mesafesi; hekimin gözü ile hastanın oklüzal düzlemi arasındaki uzaklığı ifade etmektedir. Hasta çok yüksekte konumlandırılmışsa veya diş hekimi hastanın üzerine kambur vaziyette eğilmişse, bel ağrısı meydana gelmesi kaçınılmazdır. (Resim 1,6) Uygun olmayan bu tip pozisyonlardan kaçınmak için indirekt görüş tercih edilmelidir. ${ }^{1,8}$

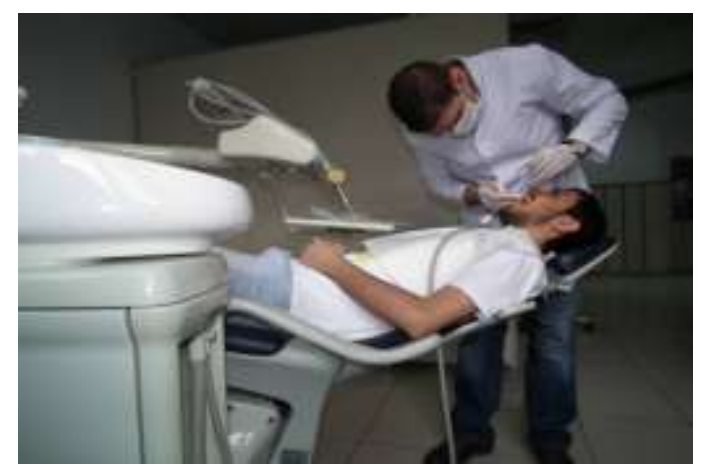

Resim 6. Bel ağrısını tetikleyebilecek kambur hekim pozisyonu.

\section{Büyütme Sistemleri}

Diş hekimliğinde operasyon mikroskobu ve magnifikasyon gözlükleri daha net görüntü elde etmek amacıyla kullanılmaktadır. Bu tip büyütme sistemlerinin kullanımıyla düzgün bel-boyun postürü sağlanabilmektedir ve bel ağrısı oluşma olasılığı azaltılabilmektedir. ${ }^{1,8,20}$ İki kat büyültmeye (x2) sahip magnifikasyon gözlüklerinin kullanımı hekimin hasta üzerine eğilmesiyle eşdeğer çalışma alanı detayı sağlamaktadır. İki kattan fazla büyültmeye sahip gözlüklerle daha detaylı görüş elde edilmektedir. ${ }^{8}$ Normal mikroskopların kullanımında başın $20^{\circ}$ öne doğru eğilmesi gerekmektedir ve bel eğiminde düzleşmeye bağlı bel ağrısı oluşabilmektedir. Bunun yerine, başın öne doğru eğilme ihtiyacını ortadan kaldırmaya yönelik tasarlanmış mikroskoplar ve görüntünün LCD ekranda izlenmesine olanak tanıyan bir ağız dışı kamera kullanmak daha iyi bir çalışma postürü sağlamaktadır. ${ }^{1,8,21}$ Operasyon mikroskobu kurulduktan sonra, hekimin el aletlerine ulaşmak için operasyon sahası çevresinin uygun şekilde düzenlenmesi gerekmektedir. Hekim aletlere ulaşmak için ellerini operasyon sahasından ayırmamalı, el aletleri bir diş hekimi yardımcısı tarafından hekime verilmelidir. ${ }^{22}$ Mikroskop sistemi alırken;

- Çalışma mesafesi,

- Alan derinliği,

- Sapma açısı,

- Yakınsaklık açısı,

- Büyültme faktörü,

- Işık intiyacı gibi hususlara dikkat edilmelidir. ${ }^{1,8,22}$

\section{Baş Desteğinin Ayarlanması}

Baş desteğinin hastanın başını tam olarak desteklediğinden ve hastanın rahat olduğundan emin olunmalıdır. Eğer baş desteği çok uzunsa, diş hekimi hastaya ulaşmak için öne doğru eğilir, bu durum da bel ağrısına sebebiyet vermektedir. Hasta koltuğunun baş desteği ne kadar küçük olursa, hekimin bacaklarının hareketi için 0 kadar serbestlik sağlanmaktadır. ${ }^{1,12}$

\section{Alet Seçimi}

Diş hekimliğinde kullanılan aletlerin tasarımı, uygulanan kuvveti azaltacak ve el/bilek pozisyonun normal postürde olmasını sağlayacak biçimde olmalıdır. ${ }^{1}$ Diş hekimliğinde kullanılan aletler firmadan firmaya farklılık göstermektedir. Aletler, sapının ince, ağır ve sert olması için, genellikle metalden özellikle paslanmaz çelikten üretilmektedir. İdeal bir dental alet 
en az $10 \mathrm{~mm}$ çapa ve $15 \mathrm{~g}$ ağırlığa sahip olmalıdır. Son yıllarda, hekim tarafından rahat kullanılabilmesi için ergonomik tasarıma önem veren aletler üretilmektedir. ${ }^{3}$ Özellikle hekimin kullandığı eline yönelik sağ/sol tasarımlı aletlere günümüzde ulaşmak mümkündür.

Alet seçimi yaparken;

- Toplam boyutu ve şekli,

- Sapın boyutu ve şekli,

- Ağırlığı,

- Dengesi,

- Kullanım kolaylığı,

- Bakım kolaylığı gibi faktörler değerlendirilmelidir. ${ }^{1,8}$ İdeal bir el aleti;

- İçi boş veya rezin saplı olmalı,

- Yuvarlak, tırtıklı ve yumuşak sapı olmalı,

- Adi çelikten üretilmiş olmalıdır (keskin kenarlı olan aletler için). ${ }^{1,3}$

İyi bir dental başlık;

- Hafif ve dengeli olmalı (kablosuz olanlar tercih edilmeli),

- Uygun güç sağlamalı,

- Işık kaynağı içermeli,

- Düz sap yerine açılı sapa sahip olmalı,

- Esnek, hafif hortumları/kabloları bulunmalı,

- Dönel mekanizmaya sahip olmalı,

- Kolay çalıştırılmalı,

- Bakımı kolay olmalıdır. ${ }^{1}$

\section{Pedalın Konumu}

Diz açısının 90-100 olmasına imkan verecek şekilde diş hekimine yakın olmalıdır. (Resim 2) Pedal diz açısının artmasına sebebiyet verecek kadar uzakta konumlanırsa, hekim pedala ulaşmak için ağırlığını tek bir tarafa verir, bu durum belde asimetrik streslerin açığa çıkmasına ve belde ağrıya neden olur. (Resim 1) Gün içersinde pedalı kullanan ayak 2-3 sefer değiştirilmelidir. ${ }^{1,8}$ Ayak pedala düz bir doğrultuda basmalıdır. ${ }^{1}$

\section{Aydınlatma ve Reflektörün Konumu}

Bir alana verilen ışığın kantitesi footcandle ışık ölçüsü ile belirlenir. Klinik çalışma ortamının aydınlatılması için 200-250 footcandle yeterlidir. Bunun üstündeki değerler gözü yorar, altındaki değerler ise hataların algılanmasına engel olur. ${ }^{17}$ Diş hekimliği pratiğinde, reflektörün konumu genellikle doğru bir şekilde ayarlanamamaktadır. Gölgesiz ışıklandırmanın sağlanabilmesi için reflektörden çıkan ışık demetleri muayene yapılan doğrultuya paralel olmalıdır. ${ }^{4}$

\section{Çalışma Saatlerinin Ayarlanması}

Hasta randevuları ayarlanırken, kronik kas yorgunluğuna maruz kalmamak için dinlenmeye yeterli zaman ayrılmalıdır. Zor vakalarda seanslar için ayrılan süre arttırılmalıdır. ${ }^{1,8}$ Hastaların takip randevularının aralığı kısa tutulmalıdır. Esnek randevu sistemiyle zor ve kolay işlemlerin yeri birbiriyle değiştirilmelidir. ${ }^{1}$

\section{Kısa Aralar}

Diş hekimi operasyon esnasında rahatlamak için sık sık ara vermelidir. ${ }^{1}$ Lokal anestezinin etki göstermesini beklerken, eldiven giyerken, diş hekimi asistanı simanı, ölçü maddesini karıştıııken ve polimerizasyon için ışıklama yaparken esneme hareketleri yapmalıdır. ${ }^{1,8}$ Esneme hareketlerinin yanısıra ön kollar diş hekimi koltuğundaki desteğe konarak dinlendirilmelidir. ${ }^{1}$

Uzun süreli statik kas kontraksiyonunu önlemek için hareket halinde bulunmak gerekmektedir. Biraz oturarak biraz da ayakta durarak çalışmak, farklı kas gruplarını harekete geçirir., ${ }^{8,12}$ Ayakta dururken de ağırlığın verildiği ayağın sık sık değiştirilmesi tek bir bel kası grubunun kasılmasını önler. ${ }^{8}$ Örnek vermek gerekirse; ölçü alınması, diş çekimi gibi işlemleri ayaktayken yapmak kuvveti vücudun bir bölgesinden diğer bir bölgesine aktarır. Ayrıca hastanın başı etrafında çalışma pozisyonunu değiştirmek de kuvvetin kas bölgeri arasında değiştirilmesini sağlar. ${ }^{1}$

\section{Esneme Hareketleri}

Kas iskelet sisteminin sağlığı için, esneme hareketlerinin gün içersinde rutin olarak yapılan bir aktivite haline getirilmesi önemlidir. Sık sık yapılan geriye doğru esneme hareketi, kas iskelet rahatsızlığına ve ağrıya neden olan kas dengesizliğini önler. ${ }^{1,8,12}$ Uygun olsun ya da olmasın ne tür pozisyonda çalışılırsa çalışılsın kısa aralıklarla verilen molalarda yapılan esneme hareketleri; iskemi, kas dengesizliği, tetik noktası, eklem hipomobilitesi, sinir baskısı ve disk dejenerasyonu gibi durumların açığa çıkmasını önler. ${ }^{8}$ Ayrıca esneme hareketleri;

- Kaslara kan akışını arttırır,

- Eklemde sinoviyal sıvı üretimini arttırır,

- Tetik noktaları oluşumunu azaltır,

- Eklemin normal sınırlar dahilinde hareketinin devamlılığını sağlar,

- Merkezi sinir sisteminde bir rahatlama cevabı oluşturur,

- Yaralanmaya meyilli yapıları sıkılaştırır. ${ }^{8,12}$ 
Esneme hareketleri yaparken sakatlanmamak için;

- Esneme için başlangıç noktası belirlenmelidir,

- Derin nefes alınmalıdır,

- Esneme pozisyonunda iki ile dört nefes alıp verme süresi kadar beklenmelidir,

- Esneme hareketinin etkinliğini arttırmak için yavaş yavaş nefes verilmelidir,

- Esneme pozisyonundan normal pozisyona yavaşça dönülmelidir,

- Eğer vakit varsa esneme hareketleri tekrarlanmalıdır,

- Ağrı sınırına kadar esnenmelidir. Eğer ağrı oluşuyor veya artıyorsa esneme hareketine devam edilmemelidir,

- Hem sağa hem de sola doğru esneme hareketleri yapılmalıdır,

- Çalışma esnasında yapılan esnemelerde öncelik sıkı tarafa verilmelidir. Evde her iki tarafa doğru esneme hareketleri yapılmalıdır. ${ }^{8}$

Diş hekimi kendisine uygun olan esneme hareketleri ve sakatlanmaları önlemek için doktorunun tavsiyelerine uymalıdır. ${ }^{1,8}$

\section{Güçlendirme Egzersizleri}

Bel ağrılarını önlemek için diş hekimi, gövdeyi stabilize eden kasların dayanıklıı̆ı̆ı arttırmaya yönelik hareketler yapmalıdır. Gövdeyi stabilize eden kaslar; m.transversus abdominis, m.erector spinae, m.abdominis internal oblique ve m.abdominis external oblique'dır. M.erector spinae, geriye doğru uzanmayı; m.abdominis internal oblique, gövdenin üst yarısının, m.abdominis external oblique, gövdenin alt yarısının hareketini sağlar. ${ }^{1}$ Dönme hareketi esnasında her iki oblik kas birlikte çalışır. M.quadratus lumborum kası ise vücudun yana doğru eğilme hareketini yaptırır.,12

Diş hekimi kaslarını güçlendirmek için bir egzersiz programına başlamadan önce doktor kontrolünden geçmelidir. ${ }^{8}$ Genellikle sırtın ve gövdenin güçlendirilmesi amacıyla bir pilates topu yeterli olmaktadır. ${ }^{1}$ Aerobik hareketleri haftada 3-4 kez 20 dakikaya süreyle yapmak, kas iskelet rahatsızlıklarının açığa çıkmasında esas faktörler olan, kasların yeterince beslenememesi ve oksijen alamamasını önlemede etkilidir. ${ }^{23}$ Ayrıca vücut ağırlığı da önemlidir, çünkü fazladan her 5 kilo bele 50 kilo yük bindirir. ${ }^{1}$

\section{Stres Yönetimi}

Diş hekimliğinin stresli bir meslek dalı olduğu yadsınamaz bir gerçektir. Stres, özellikle trapezius kasında, kontraksiyona ve ağrıya neden olabilmek- tedir. ${ }^{24}$ Diş hekimleri stres kaynaklı kas gerilmelerini azaltmak için nefes alıp-verme egzersizleri, progresif gevşeme, masaj, aerobik egzersizleri, meditasyon, yoga gibi çeşitli stres yönetimi tekniklerini uygulayabilirler. $^{8}$

\section{SONUÇ}

Diş hekimleri, çalışma koşulları nedeni ile stres ve ağrı açısından risk altındaki meslek çalışanları arasındadır. Ergonominin diş hekimliğinde başarılı bir şekilde uygulanmasıyla, üretkenlik ve verim arttırılabilir, hastalık ve sakatlıklardan korunulabilinir. Çalışma ortamının ergonomik olmaması durumunda çalışma kaynakı iskelet kas rahatsızıkları görülebilir.

Uygun postür ve pozisyon stratejilerinin uygulanması, ergonomik alet ve ekipmanların kullanılması, ergonomik koşullarla ilgili düzenlemelerin yapılması (gürültü, aydınlatma, hasta birikimi, aletler ve dinlenme yerleri vb.), operasyonlar sırasında dört-elli diş hekimliği konseptinin uygulanması, hasta muayeneleri arası sürenin arttırılması, esneme hareketleri için sık sık ara verilmesi, güçlendirme egzersizlerinin yapılması, düzenli egzersizin yaşamın bir parçası haline getirilmesi, dengeli beslenme, ağrı ve stresle başa çıkma yöntemlerinin öğrenilmesi, diş hekiminin çalışmasını kolaylaştıracak, daha dengeli kas iskelet sistemine kavuşmasını, üretkenliğin arttırılmasını, daha güvenli çalışma alanı oluşturulmasını, kas iskelet rahatsızlıklarının önlenmesini, mesleğin uzun yıllar başarılı ve sağlıklı bir şekilde sürdürülebilmesini sağlayacaktır.

\section{KAYNAKLAR}

1. Gupta S. Ergonomic Applications to Dental Practice. Indian J Dent Res 2011;22:816-22.

2. Subasi N, Topbasi N, Ulker G, Tahtaci T, Aydemir $\mathrm{N}$, Cilingiroglu N. Dimension of Musculo-Skelatal System Pain and its Effect on Health Related Life Quality Among Dentists in an Oral-Dental Health Center. Hacettepe Dishek Fak Derg 2005;29: 4250.

3. Simmer-Beck M, Branson BG. An Evidence-Based Review of Ergonomic Features of Dental Hygiene Instruments. Work 2010;35:477-85.

4. Garbin AJ, Garbin CA, Diniz DG, Yarid SD. Dental Students' Knowledge of Ergonomic Postural

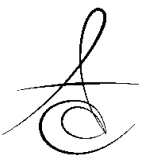


Requirements and Their Application During Clinical Care. Eur J Dent Educ 2011;15:31-5.

5. Greathouse DG, Pickens BB, Root TM, Sutlive TG, Carrillo CR, Shaffer SW, et al. Clinical and Electrodiagnostic Abnormalities of The Median Nerve in Army Dental Assistants Before and After Training as Preventive Dental Specialists. US Army Med Dep J 2011;11:70-81.

6. Garbin AJ, Garbin CA, Moimaz SA, Baldan RC, Zina LG. Dental Practice and Musculoskeletal Disorders Association: a Look at The Evidence. Arch Environ Occup Health 2011;66:26-33.

7. Hjalmers K, Soderfeldt B, Axtelius B. Psychosomatic Symptoms Among Female Unpromoted General Practice Dentists. Swed Dent J 2003;27:35-41.

8. Valachi B, Valachi K. Preventing Musculoskeletal Disorders in Clinical Dentistry. J Am Dent Assoc 2003;134(12):1604-12.

9. Castro SL, Figlioli MD. Ergonomics Applied to Dentistry: Evaluation of Posture and Work Positions of The Dentist and the Assistant Handed Dentistry in Restorative Procedures. JBC J Bra's Clin Estet Odontol 1999;3:56-62.

10. Murtomaa H. Conceptions of Dentists and Dental Nurses About Ergonomic. Ergonomics 1983;26:879-86.

11. Saunders H, Saunders R. Educational Opportunities. Evaluations, Treatment and Prevention of Musculoskeletal Disorders: Spine. Vol 1. $3^{\text {rd }}$ ed. Chaska, Minnesota: Saunders Group;1995. p.7.

12. Valachi K, Valachi B. Mechanisms Leading to Musculosketetal Disorders in Dentistry. J Am Dent Assoc 2003; 134:1344-50.

13. Alexopoulos EC, Stathi IC, Charizani F. Prevalence of Musculoskeletal Disorders in Dentists. BMC Musculoskeletal Disord 2004;5:16.

14. Dong H, Loomer P, Barr A, Laroche C, Young E, Rempel D. The Effect of Tool Handle Shape on Hand Muscle Load And Pinch Force in a Simulated Dental Scaling Task. Appl Ergon 2007;38:525-31.

15. Hayes M, Cockrell D, Smith DR. A Systematic Review of Musculoskeletal Disorders Among Dental Professionals. Int J Dent Hyg 2009;7:159-65.
16. Harrison D, Harrison S, Croft AC, Harrison DE, Troyanovich SJ. Sitting Biomechanics, Part 1: Review of Literature. J Manipulative Physiol Ther 1992;22:594-609.

17. Karacaer Ö, Yaluğ S, Yavuzyılmaz H. Diş Hekimliğinde Ergonometri. Ataturk Univ Dis Hekim Fak Derg 1995;5:101-4.

18. Mangaram J, McGlothlin JD. Ergonomics and Dentistry: A literature Review. In: Murphy $D$, ed. Ergonomics and the Dental Worker. Washington, DC: American Public Health Association; 1998. p.25-82.

19. Thornton $\mathrm{U}$, Barr AE, Stuart-Buttle C, Gaughan JP, Wilson ER, Jackson AD, Wyszynski TC, Smarkola C. Perceived Musculoskeletal Symptoms Among Dental Students in the Clinic Work Environment. Ergonomics 2008;51:573-86.

20. Chang BJ. Ergonomic Benefits of Surgical Telescope Systems: Selection Guidelines. J Calif Dent Assoc 2002;30:161-9.

21. Ariens G, Bongers $P$, Douwes M, Miedema MC, Hoogendoorn WE, van der Wal G, Bouter LM, van Mechelen W. Are Neck Flexion, Neck Rotation, and Sitting at Work Risk Factors for Neck Pain? Results of a Prospective Cohort Study. Occup Environ Med 2001;58:200-7.

22. Uzun O, Yalpı F. Endodontide Büyütme ve Aydınlatma. GÜ Diş Hek Fak Derg 2012;29:51-61.

23. McArdle W, Katch F, Katch V. Leg and Ankle. In: Exercise Physiology: Energy, Nutrition and Human Performance. 3rd ed. Philadelphia: Lea \& Febiger; 1991. p.698-735.

24. Westgaard RH. Effects of Physical and Mental Stressors on Muscle Pain. Scand J Work Environ Health $1999 ; 25: 19-24$.

\author{
Yazışma Adresi \\ Arş.Gör.Dt. Emre TOKAR \\ Gazi Üniversitesi \\ Diş Hekimliği Fakültesi \\ Bişkek Cd. (8. Cd.) \\ 82. Sk. No:4 06510 Emek-ANKARA \\ Email: emretokar@yahoo.com
}

